\title{
Exploring the usefulness of indicators for referring people with dementia and their informal caregivers to activating interventions: a qualitative analysis of needs assessments
}

Netta Van't Leven ${ }^{1 *}$ (D), Jacomine de Lange', Johanna Groenewoud', Eva van der Ploeg ${ }^{2}$ and Anne Margriet Pot ${ }^{3,4}$

\begin{abstract}
Background: People with dementia (PWDs) and their informal caregivers frequently report difficulties in maintaining their usual activities. We had previously developed a set of indicators to estimate whether dyadic, activating interventions can meet these needs for activity. This study investigates how PWDs and informal caregivers talk about the indicators in interviews for needs assessments, and how professionals identify activity needs and preferences. Our research goal was to explore the usefulness of the indicators for assessing the activity needs of community-dwelling dyads. Such assessments are needed for appropriate referral to activating interventions.
\end{abstract}

Methods: A dementia case manager assessed the needs of community-dwelling PWDs and their informal caregivers; we carried out secondary analyses on the dataset resulting from the audio-tapes and transcripts. We applied qualitative, deductive content analysis because we wanted to identify both explicit and implicit needs and preferences. We used the indicators that we had developed in previous research as codes.

Results: Both PWDs and informal caregivers do explicitly mention needs, preferences, and characteristics related to the indicators in the needs assessments. Possible implicit needs and preferences were frequently identified in their stories.

Conclusions: Needs-driven care requires high-quality needs assessments. Both PWDs and their informal caregivers need encouragement to express their latent needs and preferences. In addition, latent needs and preferences have to be further explored in needs assessments to find out the real meaning. The outcomes of this study highlight the significance of structured needs assessments for mapping the activity needs of PWDs and their informal caregivers. Many PWDs and informal caregivers reported activity needs, which suggests that activating interventions may be appropriate. The indicators can help professionals identify activity needs so that they can discuss matching activating interventions with the dyad.

Keywords: Dementia, Caregivers, Activity needs, Person-centred care, Psychosocial interventions, Exercise, Occupational therapy, Pleasant events

\footnotetext{
* Correspondence: m.a.van.t.leven@hr.nl

${ }^{1}$ Research Centre Innovations in Care, Rotterdam University of Applied

Sciences, Rochussenstraat 198, 3015, EK, Rotterdam, The Netherlands

Full list of author information is available at the end of the article
}

(c) The Author(s). 2019 Open Access This article is distributed under the terms of the Creative Commons Attribution 4.0 International License (http://creativecommons.org/licenses/by/4.0/), which permits unrestricted use, distribution, and reproduction in any medium, provided you give appropriate credit to the original author(s) and the source, provide a link to the Creative Commons license, and indicate if changes were made. The Creative Commons Public Domain Dedication waiver (http://creativecommons.org/publicdomain/zero/1.0/) applies to the data made available in this article, unless otherwise stated. 


\section{Background}

People with dementia (PWDs) encounter all kinds of difficulties in maintaining their activities of daily living and social functioning. They need support and care to manage their everyday life [1]. Informal caregivers often provide most of the care and support for communitydwelling PWDs [2]. They may have difficulties helping the PWDs with daily activities and maintaining their own activities at the same time due to stress and a lack of time [2,3]. The PWDs and their informal caregivers often have difficulty adapting the daily routine to their changing capacities [4-6].

Dyadic activating interventions aim to increase a dyad's skills to continue meaningful activities and cope with diminishing capacities [7-11]. The overall evidence for their efficacy is heterogeneous [12, 13]. Nevertheless, dyads who participated in these interventions, felt empowered by having been offered solutions for their most important activity needs. Such solutions came from in-depth assessments of their capacities and limitations [14]. After disclosure of the diagnosis, PWDs receive little advice about dyadic activating interventions that focus on maintaining daily functioning and social roles $[15,16]$.

Dyadic activating interventions should match dyads' needs, characteristics, and preferences [17, 18]. Individual needs and preferences for support vary largely, depending on the personal setting, health and comorbidity, and the coping style of both the PWD and their informal caregiver [19-21]. In a qualitative study, we found that dyads who wish to remain active and are open to alternative ways of going about their daily activities, might profit from these interventions [22]. Identifying activity needs, personal characteristics, and preferences is a prerequisite for estimating the appropriateness of interventions for a dyad [17]. Because needs and preferences may be latent or expressed implicitly, probing questions can help reveal them [23, 24].

To help professionals explore the activity needs, characteristics, and preferences of dyads, we developed a set of indicators for referral on the basis of the findings of the qualitative study. The set of 31 indicators was divided into five themes: 'Need for activities', 'Timing and openness', 'Lifestyle', 'Doing things apart or together' and 'Meaning of activities' (Table 1).

The theme 'Need for activities' appeared to be the central theme, and the other themes provide guidance for determining the type of activities that may be most appropriate. The indicators of 'Timing and Openness' are related to acceptance and readiness for interventions that make use of adaptations of activities and environment, and encourage changing daily routines. The 'Lifestyle' indicators facilitate choosing the type of activities that motivate the dyad. The indicators of 'Doing things apart or together' relate to preferences and routines of a dyad in their relationship and to the changing interdependence between the PWD and informal caregiver. The indicators concerning the 'Meaning of activities' may help in identifying the goals and objectives that are important to the dyad, such as having a fixed routine in the day, just passing time doing something at hand, being physically active, maintaining social contacts, maintaining independency, addressing safety inside and outside the house, or addressing physical limitations that hinder activities. A panel of clinicians recognised most of the indicators in their clinical practices [25]. The panel confirmed that needs assessment is a multi-layered process in which needs and preferences often have to be coaxed out of the dyad's stories [25]. To explore the usability of the indicators in clinical practice, the current study investigated how PWDs and their informal caregivers talked about the indicators in needs assessments and how professionals identified these needs and preferences. Our research goal was to explore the usefulness of indicators in assessing the activity needs of community-dwelling people with dementia and their informal caregivers for appropriate referral to activating interventions.

\section{Methods}

\section{Study design}

We used a qualitative approach to identify needs, preferences, and characteristics as described in the indicators [26]. Latent needs and preferences can be interpreted from the stories told in the interviews [27]. For this study, we used data collected for the VitaDem project in our secondary analysis. The integral needs-driven approach developed in the 3-year VitaDem project (2015-2018) was intended to enhance functional independence and social inclusion of community-dwelling PWDs and their informal caregivers [28-30]. The purpose of the needs assessment in the VitaDem project was to reveal individual needs and the dyad's shared needs of selfsufficiency, vitality, and social inclusion. Needs to maintain daily activities were part of the semi-structured needs-assessment interviews, by dementia case managers. The level of education of the dementia case managers was comparable to higher professional education, completed with clinical experience (1-25 years). For this project they were trained to explore the stories of the PWDs and caregivers in depth and to avoid giving solutions before exploration. The PWDs and caregivers were interviewed separately in their homes. A multi-disciplinary case conference followed for discussion of the principal needs and wishes of the dyad and brainstorming about the most appropriate tailored interventions, after clarification of these needs and wishes. 
Table 1 Presence of indicators in needs-assessment

\begin{tabular}{|c|c|c|}
\hline \multirow{2}{*}{\multicolumn{2}{|c|}{$\frac{\text { Indicators }}{\text { 1. Need for activities }}$}} & \multirow[t]{2}{*}{ Present } \\
\hline & & \\
\hline 1 & The PWD has a need for a meaningful occupational routine & 14 \\
\hline 2 & The CG has a need for advice how to cope with the behavior of the PWD & 9 \\
\hline 3 & The CG has a need for support in how to assist or instruct the PWD to perform activities & 6 \\
\hline 4 & The CG has a need for more insight into the capacities of the PWD, what he or she is able to do & 1 \\
\hline \multicolumn{3}{|c|}{ 2. Timing and openness for change. } \\
\hline 1 & The dyad is informed sufficiently about the consequences of dementia for daily life & 4 \\
\hline 2 & The CG has an understanding of the consequences of dementia for the daily activities of the PWD & 2 \\
\hline 3 & The dyad has a pro-active attitude, they want to anticipate themselves on future situations & 7 \\
\hline 4 & The dyad wants to counteract decline actively as much as possible & - \\
\hline 5 & The dyad is not focused on limitations, but on possibilities & 9 \\
\hline 6 & The dyad wants to strongly maintain their current way of living & 3 \\
\hline 7 & The PWD still has the capacity to cut out with routines (e.g. use a memory-aid) & - \\
\hline 8 & The CG is able to put energy into coping with a new approach, is not overburdened & 1 \\
\hline \multicolumn{3}{|l|}{ 3. Lifestyle } \\
\hline 1 & The dyad or one of them (PWD or CG) has or had an active lifestyle & 8 \\
\hline 2 & The PWD and/or CG likes physical activity & 15 \\
\hline 3 & The PWD and/or CG likes doing sports, in an institutional (group) setting or as a routine (running, bicycling) & 6 \\
\hline 4 & The PWD and/or CG is used to sport & 5 \\
\hline 5 & The PWD and/or CG likes outings like shopping or making a visit & 9 \\
\hline \multicolumn{3}{|c|}{ 4. Apart or together } \\
\hline 1 & The PWD is/is not accustomed to spend time alone & - \\
\hline 2 & The PWD depends a lot/ limited on CG during the day & 7 \\
\hline 3 & The PWD likes to have enjoyable shared activities with CG & 3 \\
\hline 4 & The CG has a need for enjoyable shared activities with PWD & 6 \\
\hline 5 & The CG has a strong/limited need for his or her own activities & 8 \\
\hline 6 & The CG has a need for more time for his or her own life & 10 \\
\hline \multicolumn{3}{|c|}{ 5. Meaning of activities } \\
\hline 1 & The PWD has a strong/limited need for something to do for passing time, See 1.1. & 14 \\
\hline 2 & The PWD has a strong/limited need for physical activity, See 3.2. & 15 \\
\hline 3 & The PWD has a strong/limited need for social contacts & 5 \\
\hline 4 & The PWD has a strong/limited need for self-sufficiency & 7 \\
\hline 5 & The PWD has a strong/limited need for positive experiences & - \\
\hline 6 & The PWD will benefit from adaptations or assistive devices for physical limitations & 8 \\
\hline 7 & The CG has a need for advice about safety at home & 2 \\
\hline 8 & The CG has a need for advice about safety outside & 2 \\
\hline
\end{tabular}

PWD person with dementia, $C G$ caregiver

\section{Ethical considerations}

The Medical Ethics Review Committee of the Erasmus Medical Center, the Netherlands, gave their ethical approval for the VitaDem project (MEC-2015-028). The PWDs and informal caregivers consented to audio recording of the interviews and anonymous use of the data for research.
Data and study population

Our analysis included transcripts of the two interviews for each dyad and the first part of the case conference, in which the case manager answered questions to clarify dyads' needs. Complete data with the needs assessments of 20 dyads were available. 
The case managers recruited dyads from their client databases. The inclusion criteria were: the PWD had to have a diagnosis of dementia, both the PWD and their informal caregiver had to be 65 years old or older, and both had to be living in the case manager's practice area. The exclusion criteria were inability of the candidates to express themselves in Dutch or being on a waiting list for institutionalisation (Table 2).

There was an even distribution in education level, employment history and income in the study population. The needs-assessment interviews with PWDs lasted averagely $34(12-80)$ minutes. The interviews with their informal caregivers lasted averagely 41 (18-75) minutes. The clarification part of the case conferences lasted averagely 15 (10-25) [10-25] minutes. The interviews and case conferences took place between April 2015 and March 2017. The interviews and multi-disciplinary case conferences were transcribed verbally, anonymised, and imported into Atlas-ti 7.2 for qualitative analysis.

\section{Data analysis}

We used deductive content analysis to explore how the indicators appeared in the needs assessments [31]. We carefully read three transcripts per dyad (two interviews and the clarification in the case conference), and we listened to the audio recordings of the interviews to familiarise ourselves with the stories. We sought text fragments that represented a need, characteristic, or preference related to the indicators and used the indicators as codes. The text fragment could present an explicitly mentioned present or absent need, characteristic, or preference, and it could refer to a latent need or implicit preference. Three researchers (NL, JL, and a trainee) independently coded the transcripts for the first dyad, and they discussed differences in linking text fragments to indicators. Then NL and the trainee coded the transcripts for 10 dyads. NL coded the remaining transcripts. We summarised the text fragments for indicators into a condensed description, illustrated with quotes. After analysing the needs assessments for 16 dyads, we discussed the preliminary results for their plausibility and consistency with the researchers involved in the VitaDem project (NL, JL, JG, and a researcher). To make the trustworthiness more rigorous, three researchers (JL, JG, and a researcher) coded the transcripts for one

Table 2 Study population

\begin{tabular}{lll}
\hline & Persons with dementia & Caregivers \\
\hline Mean age (range) & 81 years (68-89) & 76years (48-84) \\
Men/Women & 14 Men/6Women & 5 Men/15Women \\
MMSE Mean (range) & 21.5 (10-29) \\
Dyad- relation & 19 spouses 1 mother-daughter \\
\hline
\end{tabular}

MMSE Mini Mental State Examination dyad independently to check the consistency with NL's coding. The three researchers coded nine of the ten indicators that NL had coded in that the same transcript, and we concluded that our coding was consistent to a great extent. We counted the presence of the indicators as the last step.

\section{Results}

PWDs and their informal caregivers do mention needs, preferences, and characteristics related to the indicators in the needs-assessment interviews (Table 1). Most presentations of the indicators related to the (former) 'Lifestyle' were explicit and clear. The indicators related to the other themes, however, were more often implicitly present in the clients' stories. These needs and preferences should have had further exploration in the interviews to find out the real meaning. In total, we identified 27 of the 31 indicators.

\section{The 'Need for activities' theme}

The indicator describing the PWD's need to maintain activities was present in the needs assessments of 14 dyads. Some PWDs said quite clearly that they wanted to keep doing what they were used to doing, and some mentioned specific activities, such as household activities or a hobby. A latent need for activity was recognised when a PWD said that he or she was bored or missed a daily structure. Other PWDs said that everything was going fine; they did not know of anything more they could wish for. However, their excitement when talking about past activities might suggest a latent need for current activities. Caregivers had a need for advice about how to help the PWDs. Some were irritated by the PWD's behaviour; for example, about the PWD's inactivity or a PWD gardening for hours without a pause for a meal. These examples may indicate a need for help in learning how to assist the PWD in activities, although the case managers did not explore this topic further.

\section{The 'Timing and openness' theme}

Several dyads said that they gathered information about dementia, some has already adapted their daily routines, and some said that they took future changes into account. Rejecting domestic help because one prefers to do it one's own way can represent a strong wish to stick to one's current ways.

\section{The 'lifestyle' theme}

The PWDs and informal caregivers clearly detailed their (former) lifestyles: how they spent their days, what their usual activities were, and which outings or sports they preferred. 


\section{The 'Doing things apart or together' theme}

Many informal caregivers clearly stated their need to maintain their own activities. Several dyads also mentioned the need for enjoyable shared activities. Some informal caregivers said they felt a lack of time for shared activities because the PWD attended day-care and had other appointments with care services.

\section{The 'Meaning of activities' theme}

Several PWDs and informal caregivers explained clearly what the activities meant to them, and why the activities were important to them. However, the nature of the activities (e.g., social contact, being self-sufficient, or safety) was frequently unclear and difficult to identify from the stories in the needs assessments. One PWD said that he did not miss the gardening after he gave up his allotment garden, but when encouraged to tell more, he said he missed the mate he collaborated with. Another PWD said he wanted to continue driving; probing questions made it clear that driving a car meant for him that he could keep his role of helping his wife get the groceries.

Some indicators overlapped or were difficult to distinguish from each other. The indicators about the caregiver's need for advice about how to cope with behaviour (Table 1-1.2) and how to assist the PWD in activities overlapped (Table 1-1.3). The indicators concerning the meaning of activities for passing time (Table 1-5.1) and engaging physical activity (Table 1-5.2) were difficult to distinguish from indicators belonging to the themes of 'Need for activities' (Table 1-1.1) and 'Active lifestyle' (Table 1-3.2).

See 'Availability of data and materials' for an Additional file 1 with a complete overview of the representations of all indicators in the needs assessments.

\section{Discussion}

This study shed light on how community-dwelling PWDs and their informal caregivers expressed their needs and preferences for maintaining meaningful activities, and how case managers identified these needs and preferences. Our study confirms that dyads often have needs to maintain activities. However, they need encouragement to express and to explore those needs. We frequently identified activity needs and preferences that were implicit in their stories, which should have been further explored. Preferences related to the theme of 'Lifestyle' were expressed clearly in the needs assessments, but in the other four themes 'Need for activities', 'Timing and openness', 'Apart or together', and 'Meaning of the activity', we identified latent needs and preferences. The set of indicators with guiding questions is useful for searching actively and systematically for activity needs, including latent needs and their meaning.
Influence of the study setting: limitations and strengths The transcripts of the needs assessments used for this study may not represent usual care. Improving tailored care and multi-disciplinary collaboration were important features in the VitaDem project. As a result, the needs assessment got more emphasis than it would in usual care. The dementia case managers were trained to conduct the needs-assessment interviews with a focus on maintaining daily life and ageing in place.

A strength of this study is the inclusion of needs assessment with PWDs. Interviewing PWDs for needs assessment requires a careful approach. Confidence between the PWD and the interviewer and the use of short sentences are important in interviewing PWDs, and questions need to be specific. Questions about needs may be too abstract for them, so prompts and examples were often needed to formulate their experiences, needs, and preferences. Empathy and carefully following their thoughts were essential competencies for the quality of the needs assessments.

\section{Implications for practice}

In a person-centred approach, a professional is sensitive to tracing unmet needs, including activity needs [32]. The professionals' expertise in client-centred interview skills is a prerequisite for revealing needs and preferences because PWDs and their informal caregivers often express only the needs for which they know a solution exists. They need encouragement to explore latent needs $[6,24,25]$. Our study indicates that explicit training in interview techniques is necessary for professionals in dementia care. However, when unmet needs are made explicit, a higher level of care that adds to health-related quality of life can be achieved [32]. To meet a need adequately, it is also important to explore what that need or wish means to the person. The indicators concerning the 'Meaning of activities' may help identify the goals and objectives of a dyad, such as having a fixed routine in the day, just passing time doing something at hand, being physically active, maintaining social contacts, maintaining independency, addressing safety inside and outside the house, or addressing physical limitations that hinder activities. Knowing the meaning of the activities provides clues to finding alternatives if the preferred activity is no longer possible.

Activating interventions aim to increase a dyad's skills to adapt activities and make changes in the environment or daily routines, and they require readiness [33]. Therefore, the set of indicators include questions about timing and openness for these activating interventions. In an early phase of dementia, PWDs and their informal caregivers are very aware of social and occupational deficits. Nevertheless, assessment is often limited to medical and personal care domains in usual care [4]. Dementia-care 
specialists plead for integral needs-based approaches for dementia, which are becoming more and more developed and implemented in clinical practice [34-36]. This needs-based approach is also recommended in care pathways for dementia in several West European countries $[37,38]$. With regard to activity needs, the potential benefit of activating interventions needs to be taken into account, especially in an early phase of dementia.

\section{Implications for research}

The set of indicators can be a starting point for studying implementation in clinical practice and their utility for professionals. Do they have an added value in exploring activity needs, a dyad's being ready for change, and estimating the appropriateness of activating interventions? If so, this approach to developing indicators can be applicable for other needs domains and interventions too.

\section{Conclusions}

Needs-based care can contribute to a higher level of care and quality of life for PWDs and their informal caregivers, but it requires good-quality needs assessment. More attention to exploring needs and preferences seems necessary for professionals in dementia care. The indicators can help professionals assess activity needs so that they can better discuss the appropriateness of activating interventions with a dyad.

\section{Additional file}

Additional file 1: Indicators in needs assessment. (DOCX $30 \mathrm{~kb}$ )

\section{Abbreviations}

CG : Caregiver (informal); JG: author Johanna Groenewoud; JL: author Jacomine de Lange; MMSE: Mini Mental State Examination; NL: author Netta Van 't Leven; PWD: Person with dementia; PWDs : People with dementia

\section{Acknowledgements}

The authors thank Remi Lesuis, trainee, for his contribution to coding of the transcripts, and Hajar Senhaji, researcher, for her contribution to peer review in the analysis.

\section{Authors' contributions}

All authors developed the design and methods. NL, JL, and JG coded and analysed the transcripts. All authors, NL, JL, JG, EP and AMP, discussed preliminary results and drafted the article. All authors read and approved the final manuscript.

\section{Funding}

The Rotterdam University of Applied Sciences financially supported the first author. This article represents independent research, the funding did not interference with the content of the article.

\section{Availability of data and materials}

See Additional file 1 with a complete overview of the representations of all indicators in the needs assessments.

\section{Ethics approval and consent to participate}

The Medical Ethics Review Committee of the Erasmus Medical Center, the Netherlands gave their ethical approval for the VitaDem project (MEC-2015-028). The PWDs and informal caregivers consented to audio recording of the interviews and anonymous use of the data for research.

\section{Consent for publication}

Not applicable.

\section{Competing interests}

The authors declare that they have no competing interests.

\section{Author details}

${ }^{1}$ Research Centre Innovations in Care, Rotterdam University of Applied Sciences, Rochussenstraat 198, 3015, EK, Rotterdam, The Netherlands. ${ }^{2}$ Department of Public Health \& Primary Care, Leiden University Medical Center, Leiden, The Netherlands. ${ }^{3}$ Department of Clinical Psychology, Vrije Universiteit Amsterdam, Amsterdam, The Netherlands. ${ }^{4}$ Amsterdam Public Health research institute, Amsterdam, The Netherlands.

Received: 9 March 2019 Accepted: 22 July 2019

Published online: 23 August 2019

\section{References}

1. Livingston G, Sommerlad A, Orgeta V, Costafreda SG, Huntley J, Ames D, et al. Dementia prevention, intervention, and care. Lancet. 2017;390(10113):2673-734

2. Peeters J, Van Beek A, Meerveld J, Spreeuwenberg P, Francke A. Informal caregivers of persons with dementia, their use of and needs for specific professional support: a survey of the National Dementia Programme. BMC Nursing. 2010;9(9):9.

3. Vikström S, Borell L, Stigsdotter-Neely A, Josephsson S. Caregivers' selfinitiated support toward their partners with dementia when performing an everyday occupation together at home. OTJR: Occupation, Participation and Health. 2005;25(34):149-59.

4. O'Sullivan G, Hocking C. Translating action research into practice: seeking occupational justice for people with dementia. OTJR (Thorofare $\mathrm{N} \mathrm{J}$ ). 2013;33(3):168-76.

5. Van Bruggen S, Gussekloo J, Bode C, Touwen DP, Engberts DP, Blom JW. Problems experienced by informal caregivers with older care recipients with and without cognitive impairment. Home Health Care Serv Q 2016;35(1):11-24.

6. van der Roest HG, Meiland FJ, Comijs HC, Derksen E, Jansen AP, van Hout $H P$, et al. What do community-dwelling people with dementia need? A survey of those who are known to care and welfare services. Int Psychogeriatr. 2009;21(5):949-65.

7. Gitlin LN, Winter L, Burke J, Chemett N, Dennis MP, Hauck WW. Tailored activities to manage neuropsychiatric behaviors in persons with dementia and reduce caregiver burden: a randomized pilot study. Am J Geriatr Psychiatr. 2008;16(3):229-39.

8. Graff MJL, Vernooij-Dassen MJM, Thijssen M, Dekker J, Hoefnagels WHL, Olde Rikkert MGM. Community based occupational therapy for patients with dementia and their care givers: randomised controlled trial. Br Med J. 2006:333(7580):1196-9.

9. Prick $A E$, de Lange J, Scherder E, Pot AM. Home-based exercise and support programme for people with dementia and their caregivers: study protocol of a randomised controlled trial. BMC Public Health. 2011;11:894.

10. Teri L, Gibbons LE, McCurry SM, Logsdon RG, Buchner DM, Barlow WE, et al. Exercise plus behavioral management in patients with Alzheimer disease: a randomized controlled trial. JAMA. 2003:290(15):2015-22.

11. Verkaik R, Francke A, Lahr M, Zuidervaart M. Huisbezoeken; Voorkom Somberheid bij Geheugenproblemen, handboek voor de hulpverlener (plezierige activiteitenmethode). [home visits: preventing depressive mood in memory problems, manual for the professional: pleasant activities]. Retrieved from https://www.nivel.nl/nl/publicatie/ huisbezoeken-voorkom-somberheid-bij-geheugenproblemen-handboekvoor-hulpverlener-en. Utrecht: Nivel; 2005.

12. Olazaran J, Reisberg B, Clare L, Cruz I, Pena-Casanova J, Del Ser T, et al. Nonpharmacological therapies in Alzheimer's disease: a systematic review of efficacy. Dement Geriatr Cogn Disord. 2010;30(2):161-78. 
13. Van't Leven N, Prick AE, Groenewoud JG, Roelofs PD, de Lange J, Pot AM. Dyadic interventions for community-dwelling people with dementia and their family caregivers: a systematic review. Int Psychogeriatr. 2013;25(10):1581-603.

14. Van't Leven N, de Lange J, Van der Ploeg E, Pot AM. Working mechanisms of dyadic, psychosocial, activating interventions for people with dementia and informal caregivers: a qualitative study. Clin Interv Aging. 2018.

15. Aminzadeh F, Molnar FJ, Dalziel WB, Ayotte D. A review of barriers and enablers to diagnosis and management of persons with dementia in primary care. Canadian Geriatrics J : CGJ. 2012;15(3):85-94.

16. Moniz-Cook E, Vernooij-Dassen M, Woods B, Orrell M. Psychosocial interventions in dementia care research: the INTERDEM manifesto. Aging Ment Health. 2011;15(3):283-90

17. Brooker D, Latham I. Person-Centred dementia care, making services better with the VIPS framework. Second edition: ed. London: Jessica Kingsley Publishers; 2016

18. Kitwood TM. Dementia reconsidered: the person comes first Buckingham UK: Open University press; 1997.

19. Ablitt A, Jones GV, Muers J. Living with dementia: a systematic review of the influence of relationship factors. Aging Ment Health. 2009;13(4):497-511.

20. Borsje P, Hems MA, Lucassen PL, Bor H, Koopmans RT, Pot AM. Psychological distress in informal caregivers of patients with dementia in primary care: course and determinants. Fam Pract. 2016;33(4):374-81.

21. de Vugt ME, Stevens F, Aalten P, Lousberg R, Jaspers N, Winkens I, et al. Do caregiver management strategies influences patient behaviour in dementia? Int J Geriatric Psychiat. 2004;19:85-92.

22. Van't Leven $\mathrm{N}$, de Lange J, Prick AE, Pot AM. How do activating interventions fit the personal needs, characteristics and preferences of people with dementia living in the community and their informal caregivers? Dementia. 2016.

23. Boots LM, Wolfs CA, Verhey FR, Kempen Gl, de Vugt ME. Qualitative study on needs and wishes of early-stage dementia caregivers: the paradox between needing and accepting help. Int Psychogeriatr. 2015;27(6):927-36

24. van der Roest HG, Meiland FJM, Maroccini R, Comijs HC, Jonker C, Droes RM. Subjective needs of people with dementia: a review of the literature. Int Psychogeriatr. 2007;19:559-92

25. Van't Leven N, Van der Ploeg E, de Lange J, Pot AM. Indicators to estimate the appropriateness of activating interventions for people living with dementia and for their informal caregivers. Aging Ment Health. 2017:1-8.

26. Hsieh HF, Shannon SE. Three approaches to qualitative content analysis. Qual Health Res. 2005;15(9):1277-88.

27. Murray M. Narrative psychology and narrative analysis. In: Smith JA, editor. Qualitative psychology, a practical guide to research methods. 2nd ed. London: Sage; 2008. p. 111-32.

28. Groenewoud JH, Senhaji H, Van't Leven N, de Lange J. Barriers and facilitators to improve the social network of home-dwelling people living with dementia and their family caregivers. Alzheimers Dement. 2017;13(7 Suppl):1456.

29. Groenewoud JH, Van't Leven N, Senhaji H, Döpp C, de Lange J. Vitaal blijven en meedoen voor mensen met dementie en hun mantelzorgers; de VitaDem aanpak [Vitality and participation for people living with dementia and their informal caregivers: the Vitadem approach]. Rotterdam: Kenniscentrum Zorginnovatie, Hogeschool Rotterdam [Research Centre Innovations in Care, Rotterdam University of Applied Sciences] 2018.

30. Senhaji $H$, de Lange J, Groenewoud JH, Van't Leven N. The indicated needs of Dutch people with dementia to enable 'ageing in place'. Alzheimers Dement. 2017;13(7 Suppl):495-6.

31. Elo $S$, Kyngas $H$. The qualitative content analysis process. J Adv Nurs. 2007;62(1):107-15.

32. Scholzel-Dorenbos CJ, Meeuwsen EJ, Olde Rikkert MG. Integrating unmet needs into dementia health-related quality of life research and care: introduction of the hierarchy model of needs in dementia. Aging Ment Health. 2010;14(1):113-9.

33. Gitlin LN, Rose K. Factors associated with caregiver readiness to use nonpharmacologic strategies to manage dementia-related behavioral symptoms. Int J Geriatr Psychiat. 2014;29(1):93-102.

34. Eichler $T$, Thyrian JR, Dreier A, Wucherer D, Kohler L, Fiss T, et al. Dementia care management: going new ways in ambulant dementia care within a
GP-based randomized controlled intervention trial. Int Psychogeriatr. 2014;26(2):247-56.

35. Reuben DB, Evertson LC, Wenger NS, Serrano K, Chodosh J, Ercoli L, et al. The University of California at Los Angeles Alzheimer's and dementia care program for comprehensive, coordinated, patient-centered care: preliminary data. J Am Geriatr Soc. 2013;61(12):2214-8.

36. Samus QM, Johnston D, Black BS, Hess E, Lyman C, Vavilikolanu A, et al. A multidimensional home-based care coordination intervention for elders with memory disorders: the maximizing independence at home (MIND) pilot randomized trial. Am J Geriatr Psychiatry. 2014;22(4):398-414.

37. Mahler M, Meerveld JH. Care pathway Dementia [Zorgstandaard Dementie]. Vilans: Utrecht; 2013.

38. Samsi K, Manthorpe J. Care pathways for dementia: current perspectives. Clin Interv Aging. 2014;9:2055-63.

\section{Publisher's Note}

Springer Nature remains neutral with regard to jurisdictional claims in published maps and institutional affiliations.
Ready to submit your research? Choose BMC and benefit from:

- fast, convenient online submission

- thorough peer review by experienced researchers in your field

- rapid publication on acceptance

- support for research data, including large and complex data types

- gold Open Access which fosters wider collaboration and increased citations

- maximum visibility for your research: over $100 \mathrm{M}$ website views per year

At BMC, research is always in progress.

Learn more biomedcentral.com/submissions 